\title{
MEGAFLORA DE LA FORMACIÓN PALO PINTADO (MIOCENO SUPERIOR) SALTA, ARGENTINA. PARTE II
}

\author{
LUISAM. ANZÓTEGUI \\ Facultad de Ciencias Exactas, Naturales y Agrimensura, Universidad Nacional del Nordeste, Av. Libertad 5460, 3400, \\ Corrientes, Argentina. luisaanzotegui@yahoo.com.ar \\ MARICEL YANINA HORN \\ Secretaría General de Ciencia y Técnica, Universidad Nacional del Nordeste y Centro de Ecología Aplicada del Litoral, \\ Ruta 5, km 2,5, Corrientes, Argentina. yaninahorn@ hotmail.com
}

\begin{abstract}
MEGAFLORA OF THE PALO PINTADO FORMATION (LATE MIOCENE) SALTA, ARGENTINA. PART II. Nine taxa of plant megafossils from the late Miocene Palo Pintado Formation and of the localities Quebrada del Estanque, Quebrada del Horno, Quebrada de Alfredo and Rincón del Horno, in southern Salta Province, Argentina, are presented. They comprise three new species, viz., Blechnum serrulatiformis sp. nov. (pinnae), Sapium haematospermoides sp. nov. and Cedrela fissiliformis sp. nov. (leaf impressions); stem impressions with leaves Lycopodiella aff. L. cernua Picchi Sermoli (Lycopodiaceae), Equisetum sp. and Mayaca aff. M. fluviatilis Aublet (Mayacaceae); while Ranunculodendron anzoteguiae Lutz \& Martinez (incertae sedis) is an anatomically preserved stem; rachises with pinnae is Acrostichum paleoaureum Beauchamp, Lemoigne \& Petrescu (Pteridaceae) and leaf impressions Cabomba aff. C. caroliniana A. Gray (Nymphaeaceae), Caesalpinea aff. C. stukerti Hassler (Fabaceae, Caesalpinoidea). New forms for the South American Neogene are Lycopodiella aff. L. cernua, Cabomba aff. C. caroliniana, Mayaca aff. M. fluvialitilis and A. paleoaureum. Comparing and relating habits and habitats with close related extant plants, four paleocommunities can be inferred: fresh water, marsh, riparian and xerophytic forests. As most of the comparable extant plants have a subtropical to tropical distribution in South America, it can be inferred that the Palo Pintado paleoflora developed under a humid subtropical climate, with short dry stationality.
\end{abstract}

Key words: megaflora, Palo Pintado Formation, Neogene, northwestern Argentina.

\begin{abstract}
RESUMO - Nove táxons de impressões vegetais provenientes da Formação Palo Pintado (Mioceno superior) foram coletados nas localidades Quebrada del Estanque, Quebrada del Horno, Quebrada de Alfredo e Rincón del Horno, do sul da Província de Salta, Argentina. Dentre esses, três são espécies novas: Blechnum serrulatiformis sp. nov. (pinas), Sapium haematospermoides sp. nov. e Cedrela fissiliformis sp. nov. (impressões foliares). Foram também registrados talos foliolosos de Lycopodiella aff. L. cernua Picchi Sermoli (Lycopodiaceae), Equisetum sp. e Mayaca aff. M. fluviatilis Aublet (Mayacaceae). Ranunculodendron anzoteguiae Lutz \& Martinez (incertae sedis) é um caule com nó e estrutura anatômica; Acrostichum paleoaureum Beauchamp, Lemoigne \& Petrescu (Pteridaceae) são espécimes de raques com pinas; Cabomba aff. $C$. caroliniana A. Gray (Nymphaeaceae) e Caesalpinea aff. C. stukerti Hassler (Fabaceae, Caesalpinoidea) aparecem como impressões foliares. Como novidades nos estratos do Neógeno da América do Sul, incluem-se os registros de Lycopodiella aff. L. cernua, Cabomba aff. C. caroliniana, Mayaca aff. M. fluvialitilis e A. paleoaureum. Relacionando o hábito e hábitat dos vegetais atuais afins aos fósseis aqui descriptos, infere-se que eles representam quatro tipos de paleocomunidades: de água doce, de pântanos, de florestas ripárias e xerófitas. Como a maioria das espécies afins atuais tem uma distribuição subtropical a tropical na América do Sul, infere-se que a paleoflora da Formação Palo Pintado desenvolveu-se sob um clima subtropical úmido, com curtos períodos sazonais de seca.
\end{abstract}

Palavras-chave: megaflora, Formação Palo Pintado, Néogeno, Noroeste da Argentina.

\section{INTRODUCCIÓN}

En esta contribución, se dan a conocer nueve taxones fósiles preservados en impresiones procedentes de la Formación Palo Pintado (Mioceno superior) de Argentina; de ellos Lycopodiella aff. L. cernua Picchi Sermoli (Lycopodiaceae), Equisetum sp. (Equisetaceae) y Mayaca aff. M. fluviatilis Aublet (Mayacaceae) son tallos con hojas; mientras Ranunculodendron anzoteguiae Lutz \& Martinez (incertae sedis) es un tallo con nudos y estructura anatómica preservada; Acrostichum paleoaureum Beauchamp, Lemoigne \& Petrescu (Pteridaceae) y Blechnum serrulatiformis sp. nov. (Blechnaceae), son ráquises con pinnas; Cabomba aff. C. caroliniana A. Gray (Nymphaeaceae), Caesalpinea aff. C. stukerti Hassler (Fabaceae, Caesalpinoidea), Sapium haematospermoides sp. 
nov. (Euphorbiaceae) y Cedrela fissiliformis sp. nov. (Meliaceae), son láminas foliares. Aunque la mayoría de ellos ya han sido mencionados en otras contribuciones (Starck \& Anzótegui, 2001; Anzótegui, 2006; Galli et al., 2011), es importante describirlos e ilustrarlos junto a las especies nuevas (B. serrulatiformis sp. nov., S. haematospermoides sp. nov. y $C$. fissiliformis sp. nov.). Representan una novedad en estratos del Neógeno sudamericano los hallazgos de Lycopodiella aff. L. cernua, Cabomba aff. C. caroliniana, Mayaca aff. M. fluvialitilis y A. paleoaureum. Se debe destacar, además, que A. paleoaureum y $B$. serrulatiformis sp. nov., se hallaron en forma abundante y con pinnas enteras, algunas insertas sobre el raquis. Esta preservación es inusual en el registro de megafósiles terciarios, ya que generalmente se hallan sólo porciones pequeñas (Garcia Massini et al., 2006). Por otra parte, como Blechnum, Cedrela, Caesalpinia y Equisetum poseen antecedentes en el registro fósil de la misma región, se realiza una breve reseña de los mismos. También se presenta una discusión sobre los paleoambientes donde estas plantas se han desarrollado.

Finalmente, es importante señalar que a estos nueve taxones se suman dos especies de Salvinia (Herbst et al., 1987), S. graui Herbst \& Anzótegui y S. cf. minima Baker, hojas de Nectandra saltensis Anzótegui, Schinus herbstii Anzótegui y Ficus tressensii Anzótegui, (Anzótegui, 1998) y además tres especies de Cyperocarpus y tres de Scirpites (Cyperaceae).

\section{MARCO GEOLÓGICO}

La Formación Palo Pintado está conformada por una potente pila sedimentaria con un espesor que oscila entre 700 a $1250 \mathrm{~m}$, aflora al sur de la provincia de Salta (sudoeste del Valle Calchaquí), desde la localidad de San Carlos hasta Angastaco. Estratigráficamente, integra el Grupo Payogastilla (conformado, de base a techo, por las formaciones Los Colorados, Angastaco, Palo Pintado y San Felipe) (Diaz \& Malizzia, 1983) y exhibe un conjunto de anticlinales y sinclinales, cuyos ejes se orientan con una dirección NNOSSE con disposición subparalela. Está constituida por ciclos grano y estratodecrecientes de conglomerados matriz soporte, areniscas cuarzosas y sublíticas limpias, medianas a finas, que culminan con niveles de pelitas verdes; todo lo cual ha sido interpretado como un modelo de ríos anastomosados que evoluciona, en la sección superior, a un diseño entrelazado (Díaz, 1985, 1987; Galli, et al., 2011).

La edad de estos depósitos queda acotada al lapso entre los $10.29 \pm 0.11 \mathrm{Ma}(\mathrm{K} / \mathrm{Ar}$ ) (Galli et al., 2008) y los $5.27 \pm 0.28$ $\mathrm{Ma}$ (U/Pb, zircón) (Coutand et al., 2006), es decir al Mioceno superior-Plioceno. Como los fósiles aquí presentados se disponen en la sección media basal de la columna, tendrían una edad Mioceno tardía.

\section{MATERIAL Y MÉTODOS}

Las impresiones provienen de diferentes localidades (Quebradas del Estanque, del Horno, de Alfredo y Rincón del Horno) ubicadas al sur de la provincia de Salta (Figura 1); estas localidades son portadoras también de palinomorfos (Anzótegui \& Cuadrado, 1996; Acevedo et al., 1997; Acevedo et al., 1998); escamas de peces y vertebrados (Starck \& Vergani, 1996; Starck \& Anzótegui, 2001); y bivalvos (Morton, 1992).

Las impresiones foliares se encuentran bien preservadas y algunas son abundantes, como las de Acrostichum paleoaureum, Blechnum serrulatiformis sp. nov., Cedrela fissiliformis sp. nov. y Sapium haeatospermoides sp. nov. Las dos primeras se encuentran, en la mayoría de los casos, entremezcladas formando masas de hojas. Como $A$. paleoaureum ya fue descripto en Garcia Massini et al. (2006), se brindan sólo sus dimensiones e ilustraciones, no obstante, considerando su abundancia, se agrega la variabilidad observada. Otro es el caso de las impresiones de Lycopodiella aff. L. cernua, que aunque abundantes, no ofrecen buenos detalles para su descripción. De los tres ejemplares de Caesalpinia aff. C. stuckerti solo uno (CTES-PB 12834a y b) se encuentra bien preservado y los otros muestran la forma y escasa venación; para su comparación con actuales se realizó la diafanización de varias especies actuales de Caesalpinia L., siguiendo la técnica de Dizeo de Sttrimater (1973).

En todos los casos, los fósiles se comparan mediante bibliografía con taxones fósiles del mismo género y con taxones de la flora actual depositados en el Herbario del Instituto de Botánica del Nordeste, identificado con el acrónimo CTES. Se consideran "taxones actuales afines" a los fósiles los que presentan la mayor cantidad de caracteres comunes, aunque puedan tener algunas diferencias, atribuibles quizás a cambios morfo-adaptativos producidos a través del tiempo. Las especies fósiles aquí descriptas se encuentran incluidas en el Sistema de Clasificación Natural de Cronquist et al. (1966); las de Magnoliophyta en el APG III (2009); y las de Pteridophyta en el de Tryon \& Tryon (1982).

A fin de establecer las paleocomunidades que integraban los vegetales fósiles aquí descriptos, se tienen en cuenta la bioforma y habitat de los vegetales actuales afines. La terminología empleada fue obtenida de Hickey (1979) y LAWG (1999). Las observaciones se realizaron con un microscopio estereoscópico Olympus 5251 y las fotografías fueron obtenidas con la cámara digital Olympus SP 350.

\section{SISTEMATICA PALEONTOLÓGICA}

División LYCOPODIOPHYTA
Clase LYCOPODIOPSIDA
Orden LYCOPODIALES
Familia LYCOPODIACEAE
Lycopodiella Holub, 1964

Lycopodiella aff. L. cernua (L.) Pich. Serm., 1968 (Figuras 2F, 4B)

Material principal. Quebrada del Estanque (Salta) CTES- 
PB 12839-12843, 12846-12850, estróbilos en CTES-PB 12837; 12839a y b; $12841 ; 12844 ; 12847 ; 12849$.

Descripción. Porciones de tallos con trofófilos, raíces y estróbilos. Tallos herbáceos, con ramas anisotómicas, algunas rectas y otras recurvadas. Raicillas dicotomizadas y abundantes, capilariformes, entremezcladas, sin conexión orgánica con los tallos. Trofófilos homófilos dispuestos helicoidalmente, pequeños, herbáceos, lineares deltoideos, con ápices acuminados e inflexos, márgenes lisos, parten del tallo con ángulos de $90^{\circ}$ y se disponen en forma horizontal a subhorizontal, en algunas ramas son más abundantes que en otras. En los ápices de las ramas se hallan los estróbilos sésiles, pequeños y subglobosos con esporofilos ovadodeltoideos, de disposición helicoidal más densa que la de los trofófilos.

Dimensiones. Tallos de hasta $3 \mathrm{~cm}$ de largo; raicillas de $2 \mathrm{~cm}$ de longitud; trofófilos de $0,2-0,3 \mathrm{~cm}$ de largo por $0,1 \mathrm{~cm}$ de ancho; estróbilos de 0,4-0,6 x 0,7-0,9 cm (largo por ancho).

Comparación. No se han hallado citas de Lycopodiella en el Terciario de América del Sur. Por las características, disposición, tamaño y forma de los trofófilos (pequeños, herbáceos, linear-deltoideos, extendidos horizontal a subhorizontal) y por poseer estróbilos sésiles son parecidos a la especie actual Lycopodiella cernua en Arbo et al. (2002). No obstante la especie fósil posee estróbilos más pequeños y subglobosos.

Hábito y distribución de la especie actual afín. Lycopodiella cernua es una planta cosmopolita, se desarrolla en climas templados a cálidos en ambientes ácueos pantanosos o ribereños. En Argentina (Tryon \& Tryon, 1982) crece en el Nordeste, en las provincias de Misiones, Entre Ríos y Corrientes (Zuloaga \& Morrone, 1996).

\author{
División SPHENOPHYTA \\ Clase SPHENOPSIDA \\ Orden EQUISETALES \\ FamiliaEQUISETACEAE \\ Equisetum L., 1753 \\ Equisetum sp.
}

(Figura 3A)

\section{Material principal. Quebrada del Estanque (Salta) CTES-PB 12837.}

Descripción. Porción de tallo con seis nudos y entrenudos. Los entrenudos son levemente costillados; las costillas son muy delgadas; las hojas son envainadoras y tienen ápices agudos y triangulares.

Dimensiones. Porción de tallo de 7,8 cm x 1,4 cm (largo por ancho); entrenudos de 0,9-1,1 cm de longitud; 22-25 ápices de hojas de 0,3-0,5 x 0,1 cm (largo por ancho).

Comparación. La mayoría de los ejemplares fósiles se denominan Equisetum sp., y es difícil realizar una comparación adecuada debido a que en unos se preservan tallos con bases de ramas y en otros tallos con hojas, además en algunos las descripciones son someras y sin ilustraciones debido a que fueron dados a conocer en resúmenes. En los de Formación Navidad (Mioceno) de Chile (Troncoso, 1991) y Formación Chiquimil, Mioceno superior (Equisetum sp. 1) de Argentina (Anzótegui, 2006), se describen porciones de tallos con bases de ramas, sin hojas preservadas; no obstante los diámetros de los tallos oscilan entre los mencionados en este trabajo. Otros ejemplares de Argentina, mencionados en reuniones científicas, son los de Formación Andalhuala (Plioceno), Formación Toropí (Cuaternario) y en la localidad

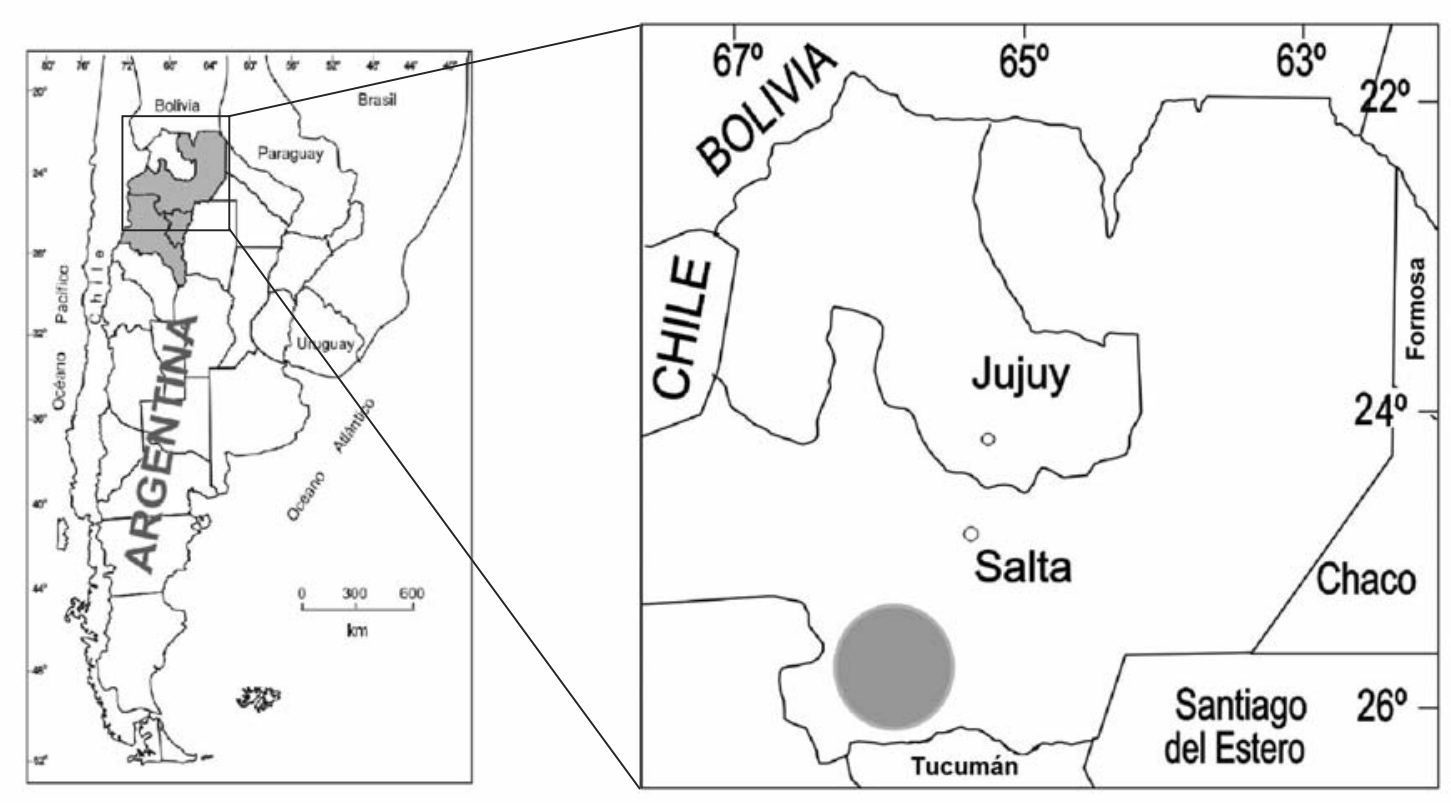

Figura 1. Ubicación geográfica de la Formación Palo Pintado. Círculo de color gris.

Figure 1. Geographic location of the Palo Pintado Formation. Gray circle. 
Villa Escolar (Holoceno), Formosa. Por último Berry (1945) en un ejemplar del Plioceno de Colombia, sólo ilustra, sin describir, un nudo con lámina envainadora y ápice dentado, el que tiene dimensiones menores al del ejemplar aquí descripto. A la mayoría de los ejemplares citados, se les otorga afinidad con la especie actual Equisetum giganteum L.

Hábito y distribución de la especie actual afín. Equisetum giganteum crece en lugares húmedos o periódicamente inundados y a orillas de cursos de agua, en el norte y centro argentino (Sota, 1977; Núñez et al., 1998; Arbo et al., 2002).

\section{División PTERIDOPHYTA Clase FILICOPSIDA Orden POLYPODIALES \\ Familia PTERIDACEAEE. D. M. Kirchn., 1831 Acrostichum L., 1753}

\section{Acrostichum palaeoaureum Beauchamp, Lemoigne \&} Petrescu, 1973

(Figuras 2A, 3B,C-H)

Material principal. Quebrada del Horno (Salta) CTES-PB 8002-8005; 8007; 8008; 8010; 8012; 8013; 8015; 8017-8020; 8025; 8028.

Dimensiones. Fragmentos de ráquises de $2-4 \mathrm{~cm}$ de largo por 0,6-1,4 cm de ancho surcados por costillas longitudinales; peciólulos, cuando presentes miden $0,4 \mathrm{~cm}$ de largo por 0,15 $\mathrm{cm}$ de ancho, se implantan sobre el raquis con ángulo de $50^{\circ}$; fragmentos de pinnas de 7-10 $\mathrm{cm}$ de largo por 3-9 $\mathrm{cm}$ de ancho. Observaciones, variabilidad: (i) base de las pinnas, desde asimétrica, decurrente-constricta a levemente asimétrica aguda, sentada o con peciólulo; (ii) ancho de las pinnas $=3$ $9 \mathrm{~cm}$; (iii) ápice simple o bifurcado; (iv) los ángulos de emergencia de las venas secundarias $20^{\circ}-90^{\circ}$, difieren en las hemiláminas de una misma pinna. El material aquí descripto, por su abundancia, variabilidad y preservación, es muy semejante al hallado en sedimentos oligocénicos de Chilga (Gondar), NW de la meseta Etíope (África), por Garcia Massini et al. (2006) y por ende a la especie actual Acrostichum aureum L. La variabilidad, el tamaño de las pinnas, la cantidad y calidad de ejemplares, estaría indicando un gran desarrollo de los vegetales, por lo que se infiere que el ambiente de sedimentación habría sido consolidado y estable. Tanto en Argentina como en el resto de América del Sur no hay trabajos previos con registro fósil del género Acrostichum; no obstante tiene una amplia y bien conocida distribución durante el Paleógeno en Norteamérica, Europa, África y Asia, generalmente representado por fragmentos pequeños (Garcia Massini et al., 2006).

Hábito y distribución de la especie actual afín. Acrostichum es un género pantropical, palustre (Tryon \& Tryon, 1982), decumbente a erecto, crece formando masas de plantas de hasta $1 \mathrm{~m}$ de diámetro, en aguas de salinidad variable desde salobres (manglares, estuarios, bahías) hasta en aguas dulces. Crece en África, en el SE de Asia y Australia, en América, desde Florida (EEUU) hasta el noreste de Argentina, a lo largo de la costa atlántica y en ríos tributarios (Zuloaga \& Morrone, 1996).

\author{
Familia BLECHNACEAE (C. Presl.) Copel., 1947 \\ Blechnum L., 1753
}

Blechnum serrulatiformis sp. nov.

(Figuras 2B, 3F-G)

Sinonimia. Blechnum sp. en Troncoso (1992), del Eoceno de Chile (Quinamavida, VII región).

Holotipo. CTES-PB 8067.

Paratipo. CTES-PB 8068 a.

Otro material. Quebrada del Horno (Salta) CTES-PB 8054b; $8056 ; 8057$; 8059-8062; 8064; 8066-8069; 14130-14136.

Etimología. Hace referencia a la similitud con la especie actual Blechnum serrulatum L.C. Rich.

Diagnosis. Pinna linear-lorate to oblong, of 5-10 cm long, 1$1.8 \mathrm{~cm}$ wide; serrate margin; acute apex with terminal tooth; asymmetrical base, obtuse/cuneate; petiole shaped like a rhomboid. Venation pinnate, midrib slightly curved has a central groove and trichome bases. Secondary veins, numerous, angle of divergence moderate-acute. Secondary veins dichotomize, usually two times, once near the midrib and the other near the margin; the apex of the secondary veins supplying the teeth.

Descripción. Frondes y raquis desconocidos. Pinnas lineares a loriformes, la mayoría se encuentra fragmentada, margen dentado con dientes simples, pequeños y con ángulo apical agudo; algunos ejemplares poseen margen liso; ápice agudo con un diente, base asimétrica, obtusa/cuneada; peciólulo, de forma romboidal. Venación pinnada, vena media levemente curvada, mide $0,5 \mathrm{~cm}$ de ancho y es de grosor moderado $(2 \%)$, posee un surco central y bases de tricomas. Venas secundarias numerosas, emergen con ángulos agudosmoderados y están separadas por espacios regulares $(0,4-0,5$ $\mathrm{cm}$ entre ellas); se observan, generalmente dos dicotomías, una próxima a la vena media y otra próxima al margen; en el área apical los ángulos de divergencia son variables y el curso de las venas es levemente curvo hacia el margen; los extremos de las venas inervan los dientes.

Dimensiones. Pinnas de 5-10 cm por 1-1,8 cm largo por ancho; ángulo de divergencia de las venas secundarias agudo a moderado $\left(40^{\circ}-60^{\circ}\right)$ en la porción media, variable desde $20^{\circ}$ a $80^{\circ}$ en el área apical.

Comparación. Blechnum sp. fue citado reiteradamente en América: en Argentina, por Baldoni et al. (1985, Formación Ventana, Eoceno); en Chile, por Troncoso (1991, 1992, Formación Navidad, Mioceno y Quinamavida, VII región, Eoceno); en Brasil, por Duarte \& Mello Filha (1980, Formación Gandarela, Eoceno). También ha sido hallado por Troncoso (1986) en el Eoceno de Antártida en la Península Fides (Isla Rey San Jorge). Se encuentran con denominación completa B. antidiluvianum Engelhardt del Eoceno inferior de Arauco Chile (Engelhardt, 1891); B. (Lomaria) turbioense Frenguelli de la Formación Río Turbio, Eoceno de la Patagonia argentina (Frenguelli, 1941) у Blechnum betijoquensis Berry del Mioceno de Betijoque (Estado de Trujillo) Venezuela (Berry, 1921). Las diferencias halladas con la especie nueva, aquí descripta, son las siguientes: las pinnas de Argentina (Baldoni 
et al., 1985) y las que describe Troncoso $(1986,1991)$ para el Eoceno de Antártida y el Mioceno de Chile, respectivamente, tienen ápices redondeados. En estas últimas (las de Chile), están insertas por toda la base y en las de Argentina la base es auriculada. Blechnum sp., de Brasil, es una porción de pinna de $3,8 \mathrm{~cm}$ de largo, más angosta $(0,7 \mathrm{~cm}$ de ancho) y con márgenes enteros, de difícil comparación porque carece de ápice y base; $B$. betijoquensis, aunque posee la misma forma y tamaño, difiere porque la base es redondeada, las venas secundarias se bifurcan una vez y los ángulos de divergencia son regularmente anchos; $B$. antidiluvianum está basado en fragmentos con márgenes lisos y venas secundarias sin bifurcación. En tanto que Blechnum sp., del Eoceno de Chile, es muy semejante a $B$. serrulatiformis $\mathrm{sp}$. nov., aquí descripto, debido a ello es incluido en sinonimia. Los caracteres que posee esta especie fósil se encuentran comprendidos en la variabilidad que presenta la especie actual Blechnum serrulatum L.C. Rich. Se justifica la creación de
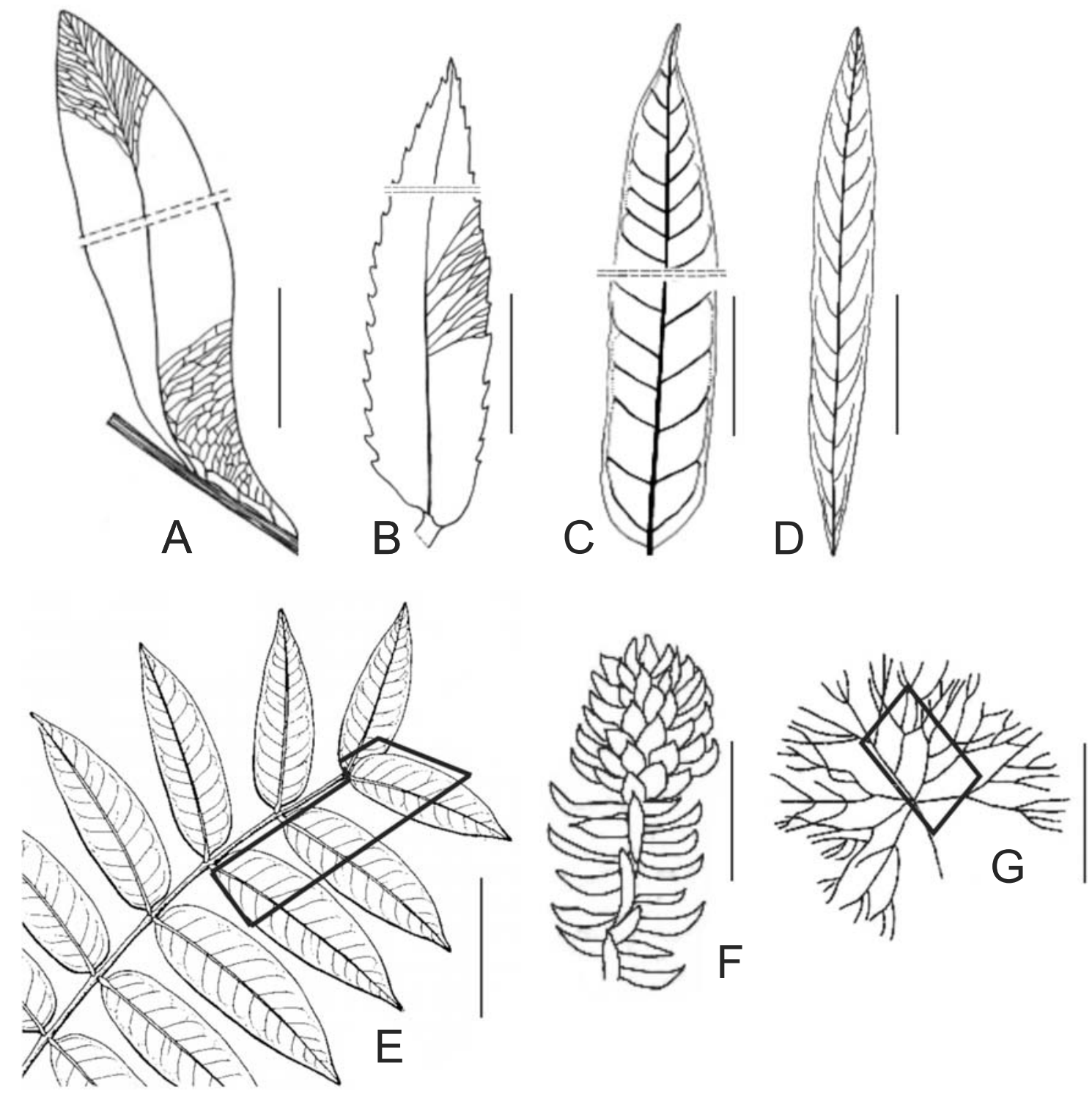

Figura 2. Representaciones esquemáticas. A, Acrostichum paleoaureum Beauchamp, Lemoigne \& Petrescu, con base asimétrica decurrente (reconstrucción) CTES PB 8020 y 12803b. B, Blechnum serrulatiformis sp. nov. CTES-PB 8067. C, Cedrela fissiliformis sp. nov. (reconstrucción) CTES-PB 8028a (base) y CTES-PB 8028c (ápice). D, Sapium haematospermoides sp.nov. (reconstrucción) CTESPB 10791. E, Cedrela fissilis Vell., actual, porción apical de una hoja compuesta (obtenida de Pennington, 1981), el recuadro indica la porción preservada en figura 5A. F, Lycopodiella aff. L. cernua (L.) Pich. Serm. CTES-PB 12844. G, Cabomba aff. C. caroliniana A. Gray, actual (obtenida de Hoehne, 1955), el recuadro indica la porción preservada en figura 3J. Escalas: $A-D=3 \mathrm{~cm} ; E=0,25 \mathrm{~cm} ; F=0,1 \mathrm{~cm} ; G=2 \mathrm{~cm}$.

Figure 2. Schematic representations. A, Acrostichum paleoaureum Beauchamp, Lemoigne \& Petrescu, with asymmetric base decurrent (reconstructión) CTES PB 8020 and12803b. B, Blechnum serrulatiformis sp. nov. CTES-PB 8067. C, Sapium haematospermoides sp. nov. (reconstruction) CTES-PB 10791a. D, Cedrela fissiliformis sp. nov. (reconstruction) CTES-PB 8028a (base) y CTES-PB 8028c (apex). E, Cedrela fissilis Vel., current (obtained from Pennington, 1981) apical portion of a compound leaf, the box indicates the portion preserved in figure 5A. F, Lycopodiella aff. L. cernua (L.) Pich. Serm. CTES-PB 12844. G, Cabomba aff. C. caroliniana A. Gray, current (obtained from Hoehne, 1955) the box indicates the portion preserved in figure 3J. Scale bars: $A-D=3 \mathrm{~cm} ; E=0,25 \mathrm{~cm} ; F=0,1 \mathrm{~cm} ; G=2 \mathrm{~cm}$. 
esta nueva especie por la coincidencia de caracteres de dos entidades, de distintos lugares y edad, y por la cantidad de ejemplares hallados en la Formación Palo Pintado.

Hábito y distribución de la especie actual afín. Blechnum serrulatum es una especie herbácea radicante, crece en bordes de bañados, lagunas y esteros (Arbo et al., 2002); tiene distribución tropical y subtropical en América, Malasia y Australia (Tryon \& Tryon, 1982); en Argentina se la encuentra en las provincias de Chaco y Corrientes (Zuloaga \& Morrone, 1996).

\section{División MAGNOLIOPHYTA Cronquist, Takht. \& W.} Zimm., 1996

Superorden NYMPHAEANAE Thorne ex Reveal, 1992

Orden NYMPHAEALES Salisb. ex Bercht. \& J. Presl., 1820

Familia CABOMBACEAE Rich. ex A. Rich., Cabomba Aubl., 1775

Cabomba aff. C. caroliniana A. Gray, 1837

(Figuras 2G, 3J)

Material principal. Quebrada del Estanque (Salta) CTES-PB 14043.

Descripción. Porciones de hojas palmatisectas con pecíolo; porción de lámina dicotomizada hasta tres veces en lóbulos lineares que se desprenden del pecíolo con ángulos agudoangostos a agudo-anchos. En la superficie, tanto del pecíolo como de los lóbulos se observa un tenue retículo.

Dimensiones. Porción de hoja de 2,5 $\mathrm{cm}$ de largo por $3 \mathrm{~cm}$ de ancho; pecíolo de $1 \mathrm{~cm}$ x 0,6 cm (largo x ancho), lóbulos lineares de $1,5 \mathrm{~cm}$ de largo por $0,25 \mathrm{~cm}$ de ancho.

Comparación. Pluricarpellatia peltata Mohr, Bernardes-deOliveira \& Taylor (ver Mohr et al., 2008) del Cretácico inferior de Brasil, por sus hojas seria similar a las hojas flotantes de la familia Cabombaceae y el fragmento de hoja fósil Cabomba aff. C. caroliniana, aquí descripto, lo es a porciones de las hojas sumergidas de la especie actual $C$. caroliniana (Hoehne, 1955; Tur, 1987).

Hábito y distribución de la especie actual afín. Cabomba caroliniana es una planta sumergida y arraigada, común en cuerpos ácueos dulceacuícolas y se la encuentra desde el este de Estados Unidos al sur de Brasil, Paraguay, Uruguay (Hoehne, 1955; Tur, 1987) y Argentina (noreste, Corrientes, Entre Ríos y en el centro, Santa Fé, Córdoba y Río Negro) (Zuloaga \& Morrone, 1999).

\section{APGIII “COMMILINIDS" \\ Orden POALES Small, 1903 \\ Familia MAYACACEAE Kunth, 1842 \\ Mayaca Aublet, 1775 \\ Mayaca aff. M.fluviatilis Aublet, 1775 \\ (Figura 3I)}

Material principal. Quebrada del Estanque (Salta) CTES-PB 12832a y b.

Descripción. Porciones de tallos curvilíneos y ramificados, algunos con hojas y otros con bases peciolares o foliares dispuestas helicoidalmente; las ramas se desprenden con ángulos agudo-anchos a rectos. Hojas lineales, lanceoladas, de disposición densa, aparentemente son uninervias, sentadas, con ápices agudos aunque escasamente preservados y con márgenes enteros, emergen del tallo con ángulo agudo ancho a recto. Bases foliares circulares; en el ápice de las ramas las hojas son mas largas y se disponen formando una corona laxa.

Dimensiones. Tallos de 1,3-5 x 0,5 cm (largo por ancho); hojas de $2 \times 0,2 \mathrm{~cm}$ (largo por ancho). Bases foliares de $0,1 \mathrm{~cm}$ de diámetro.

Comparación. No se hallaron representantes fósiles de esta familia. La especie aquí descripta por el tamaño de sus hojas es más semejante a Mayaca fluvitilis Aublet que a y $M$. sellowiana Kunth, de la flora regional; a su vez las hojas de la especie fósil son más largas $(1,5-2 \mathrm{~cm})$ que las de M.fluvitilis (que miden 0,3-1,5 cm).

Hábito y distribución de la especie actual afín. Plantas herbáceas semejantes a musgos, viven en lugares húmedos emergidas o sumergidas, en aguas tranquilas de charcos o lagunas de corriente lenta, en regiones tropicales a subtropicales de América y oeste de África. En Argentina Mayaca fluvitilis y M. sellowiana se encuentran integrando los embalsados de los estero del Iberá, en la provincia de Corrientes (Arbo et al., 2002). Siguiendo a Urquiola Cruz (2000), estas plantas por el tamaño de sus hojas habrían estado sumergidas.

Superorden RANUNCULANAE Takht. ex Reveal, 1992

Orden RANUNCULALES Jusieu ex Bercht. \& J. Presl.,1820

Familia Incertae sedis

Ranunculodendron Lutz \& Martinez, 2007

Ranunculodendron anzoteguiae Lutz \& Martinez, 2007 (Figuras 3D-E)

Material principal. Quebrada de Alfredo (Salta) CTES-PB 8049a y b (impresión de sección transversal); 10835; 10840; 10847 (silicificación mostrando el aspecto externo).

Descripción. Se describen dos tipos de preservaciones del tallo, unas, las silificaciones, que muestran el aspecto externo y otra, una impresión, donde se observa la anatomía en sección transversal. Las primeras son porciones con nudos y entrenudos que presentan en la superficie costillas algo sinuosas. La impresión de la anatomía en sección transversal es de contorno circular a subcircular y en sus márgenes presenta 12 carenas y valéculas; las primeras (carenas) son convexas hacia el exterior. En el centro, de la impresión se encuentra la médula (zona circular lisa), del borde externo de la misma irradian 12 costillas que terminan externamente en las valéculas; entre estas costillas se disponen, transversalmente a ellas, varias trabéculas, algunas bifurcadas, que delimitan los vasos (cuerpos circulares a cuadrangulares, sobreelevados), estos vasos son más grandes en el centro y disminuyen de tamaño hacia el exterior. Dimensiones. Tallo: (aspecto externo) $1,5-5 \mathrm{~cm}$ x 0,4 cm largo 

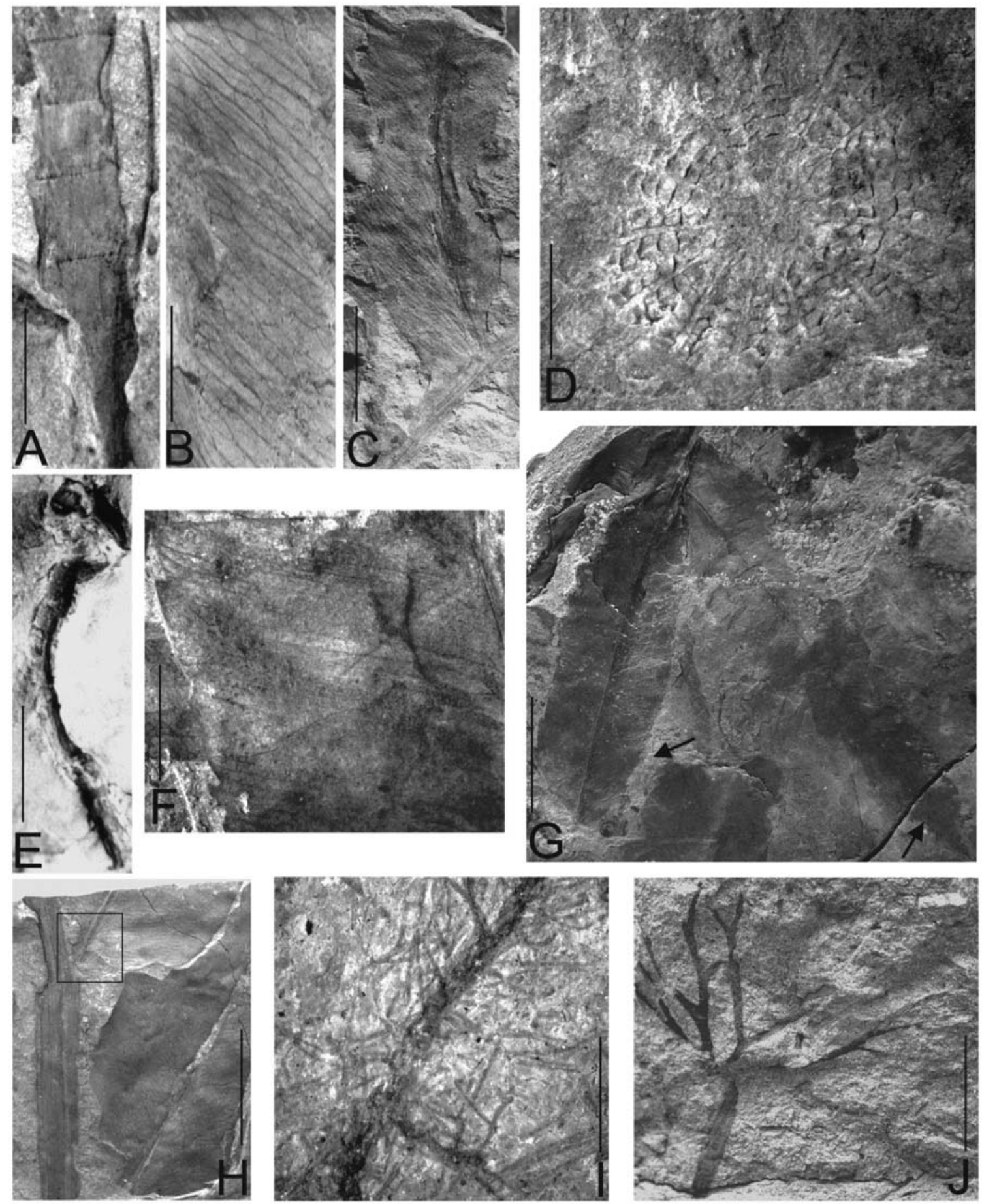

Figura 3. A, Equisetum sp. CTES-PB 12837. B-C, H, Acrostichum paleoaureum Beauchamp, Lemoigne \& Petrescu: B, detalle de la venación CTES-PB 8017; $\mathbf{C}$, porción de fronde, base de pinna decurrente CTES-PB 8020; $\mathbf{H}$, porción de fronde, el recuadro señala un peciólulo inserto sobre el ráquis CTES-PB 12803. D-E, Ranunculodendron anzoteguiae Lutz \& Martinez: D, impresión de la estructura anatómica CTES-PB 8049a; E, fragmento de tallo silicificado, CTES-PB 10835. F-G, Blechnum serrulatiformis sp. nov.: F, detalle de la venación y del margen dentado CTES-PB 8068a paratipo; G, pinna entera parcialmente plegada, las flechas señalan la base y el ápice CTES-PB 8067 holotipo. I, Mayaca aff. M. fluviatilis Aublet CTES-PB 12832. J, Cabomba aff. C. caroliniana A. Gray CTES-PB 14043. Escalas: $A=1,5 \mathrm{~cm} ; B, F=0,5 \mathrm{~cm} ; C=2,4 \mathrm{~cm} ; D=0,2 \mathrm{~cm} ; E, I=2 \mathrm{~cm} ; G=8 \mathrm{~cm} ; \mathrm{H}=2,2 \mathrm{~cm} ; \mathrm{J}=0,8 \mathrm{~cm}$.

Figure 3. A, Equisetum sp. CTES-PB 12837. B-C, H, Acrostichum paleoaureum Beauchamp, Lemoigne \& Petrescu: B, detail of the venation CTES-PB 8017; C, portion of frond, decurrent base of pinna CTES-PB 8020; $\mathbf{H}$, portion of the frond, the framed area shows a petiole inserted on rachis CTES-PB 12803. D-E, Ranunculodendron anzoteguiae Lutz \& Martinez: D, impression of the anatomical structure CTES-PB 8049a; E, silicified stem fragment CTES-PB 10835. F-G, Blechnum serrulatiformis sp. nov.: F, detail of the venation and dentate margin CTES-PB 8068a paratype; G, full pinna partially folded, base and apex are arrowed CTES-PB 8067 holotype. I, Mayaca aff. M. fluviatilis Aublet CTES-PB 12832; J, Cabomba aff. C. caroliniana A. Gray CTES-PB 14043. Scale bars: $A=1,5 \mathrm{~cm} ; B, F=0,5 \mathrm{~cm} ; \mathrm{C}=2,4$ $\mathrm{cm} ; \mathrm{D}=0,2 \mathrm{~cm} ; \mathrm{E}, \mathrm{I}=2 \mathrm{~cm} ; \mathrm{G}=8 \mathrm{~cm} ; \mathrm{H}=2,2 \mathrm{~cm} ; \mathrm{J}=0,8 \mathrm{~cm}$. 
por ancho, entrenudos de 0,5 cm de largo; (sección transversal), contorno de la impresión anatómica $0,46 \mathrm{~cm}$ de diámetro, médula $0,001 \mathrm{~cm}$ de diámetro; vasos $0,00015 \mathrm{~cm}$ de diámetro.

Comparación. Las silicificaciones del aspecto externo del tallo son semejantes a las que se procesaron para estudiar la anatomía interna en Lutz \& Martinez (2007). La impresión de la anatomía interna refleja la descripta por los autores mencionados de la siguiente manera: el centro circular y liso representa a la médula, las costillas corresponden a los radios leñosos, los cuerpos circulares a cuadrangulares a los vasos y las trabéculas al parénquima que los rodea; coincidentemente los vasos leñosos (cuerpos circulares) disminuyen de tamaño desde el centro a la periferia. Por consiguiente, por el tamaño del tallo, la disposición de los radios principales, las características y disposición de los vasos y el parénquima esta impresión corresponde a Ranunculodendron anzoteguiae. Esta descripción complementa la que realizaron los mencionados autores.

Hábitat y hábito de la especie fósil. Por las características anatómicas, Lutz \& Martinez (2007) consideran que por los "vasos numerosos y anchos con relativamente poco tejido mecánico que caracteriza a las especies de hábito escandente", Ranunculodendron anzoteguiae es una liana. A su vez, esta especie fósil, guarda relación por diferentes caracteres anatómicos con las familias actuales Menispermaceae, Aristolochiaceae, Lardizabalaceae y Vitaceae que se desarrollan principalmente en regiones subtropicales y tropicales; además, por las características sedimentológicas y por la flora acompañante, concluyen que es una liana que se desarrolló en ambientes cálidos y húmedos.

\section{Superorden ROSANAE Takht., 1967 \\ Orden FABALES Bromhead, 1838 \\ Familia FABACEAE Lindl., 1836 \\ Subfamilia CAESALPINIOIDEAEDC., 1825}

\section{Caesalpinia L., 1753 \\ Caesalpinia aff. C. stuckerti Hassler, 1913}

(Figura 4C)

\begin{abstract}
Material principal. Quebrada del Estanque (Salta) CTES-PB 12834a y b; 12853a y b; 14050 .
\end{abstract}

Descripción. Lámina asimétrica entera, obovada, (leptofila) base asimétrica cóncava/aguda, ápice mucronado o emarginado; pulvínulo desplazado hacia la parte aguda de la base. Venación pinnada, broquidódroma, vena media de tamaño moderado $(1,25 \%)$ y de recorrido recto; $4-5$ venas secundarias divergen con ángulos agudo-moderados $\left(40^{\circ} \mathrm{a}\right.$ $60^{\circ}$ ); las venas secundarias presentan venación broquidódroma festoneada. Venas intersecundarias compuestas, presentes en todos los espacios intercostales, tienen recorrido levemente sinuoso, el ángulo de divergencia con la vena media es igual al de las secundarias, en el espacio intercostal basal se observan 2 intersecundarias que se unen a mitad de recorrido. Las venas terciarias exhiben un reticulado ortogonal. Venación de orden mayor, no se observa. Venación última marginal, aparentemente ojalada.

Dimensiones. Lámina de 1,3 cm de largo por $1 \mathrm{~cm}$ de ancho. Comparación. Los folíolos fósiles asignados a este género provienen de: Argentina (Fiori, 1940), Caesalpinia sp., del Mioceno; Bolivia (Berry, 1919, 1922a), C. sessilifolioides Berry, C. gmehlingi Engelhardt y $C$. jancocatana Berry, del Mioceno inferior; Brasil (Berry, 1935), C. echinataformis Berry, del Eoceno, Formación Fonseca. En la mayoría de ellos es difícil realizar una comparación adecuada, ya que como se menciona en Anzótegui et al. (2007), se encuentran pocos elementos descriptivos y las ilustraciones no aportan muchos datos; tan es así, que recientemente, Fanton et al. (2009), con mayores detalles establecieron que $C$. echinatiformis es afin a Senna multijuga. Solamente en $C$. jancocatana se muestra claramente la forma y la venación de hasta tercer orden, pero la misma difiere de la especie fósil aquí descripta por la forma ovada-elíptica ancha, por la mayor cantidad de venas secundarias y porque no posee intersecundarias.

La presente especie fósil, por el tamaño, forma y tipo de venación, cabe dentro de la variabilidad que presentan los folíolos de la especie actual Caesalpinia stuckerti Hassler, de la flora argentina.

Hábito y distribución de la especie actual afín. Caesalpinia stuckerti es un arbusto que integra el Distrito Chaqueño Occidental de la Argentina, en las provincias de Chaco, Formosa, Santa Fé, Santiago del Estero y Tucumán (Cabrera, 1976); constituyendo los bosques xerófilos, es una de las especies endémicas que no crecen en otros sectores fuera del parque chaqueño (Ragonese \& Castiglioni, 1970).

Orden MALPIGHIALES Juss. ex Bercht. \& J. Presl., 1820 Familia EUPHORBIACEAE Marc.-Berti, 1989 Sapium Jacq., 1760

Sapium haematospermoides sp. nov. (Figuras 2D, 4A,D-G)

Holotipo. Quebrada del Estanque (Salta) CTES-PB 10791a. Paratipo. CTES-PB 10795.

Otro material estudiado. Quebrada del Estanque (Salta): CTES-PB 10779ay b; 10781; 10792-10794; 10796-10798; 10801a y b; 10805 .

Etimología. Hace alusión a la especie actual Sapium haematospermum Müll. Arg.

Diagnosis. Linear to lorate leaf (nanophyll), apex attenuate and base cuneate with petiole, margins entire. Venation pinnate eucamptodromous, midrib stout to massive size, course straight, contains longitudinal grooves. Twenty or more secondary veins, angle divergence moderate; one pair of lower and upper secondary veins more narrow than middle set; secondary vein spacing uniform; intersecundaries veins simple, angle divergence wide acute; tertiary veins random reticulate. Quaternary veins polygonally reticulated; areolation well developed areolas 3-5 sided. Marginal ultimate venation is looped. 

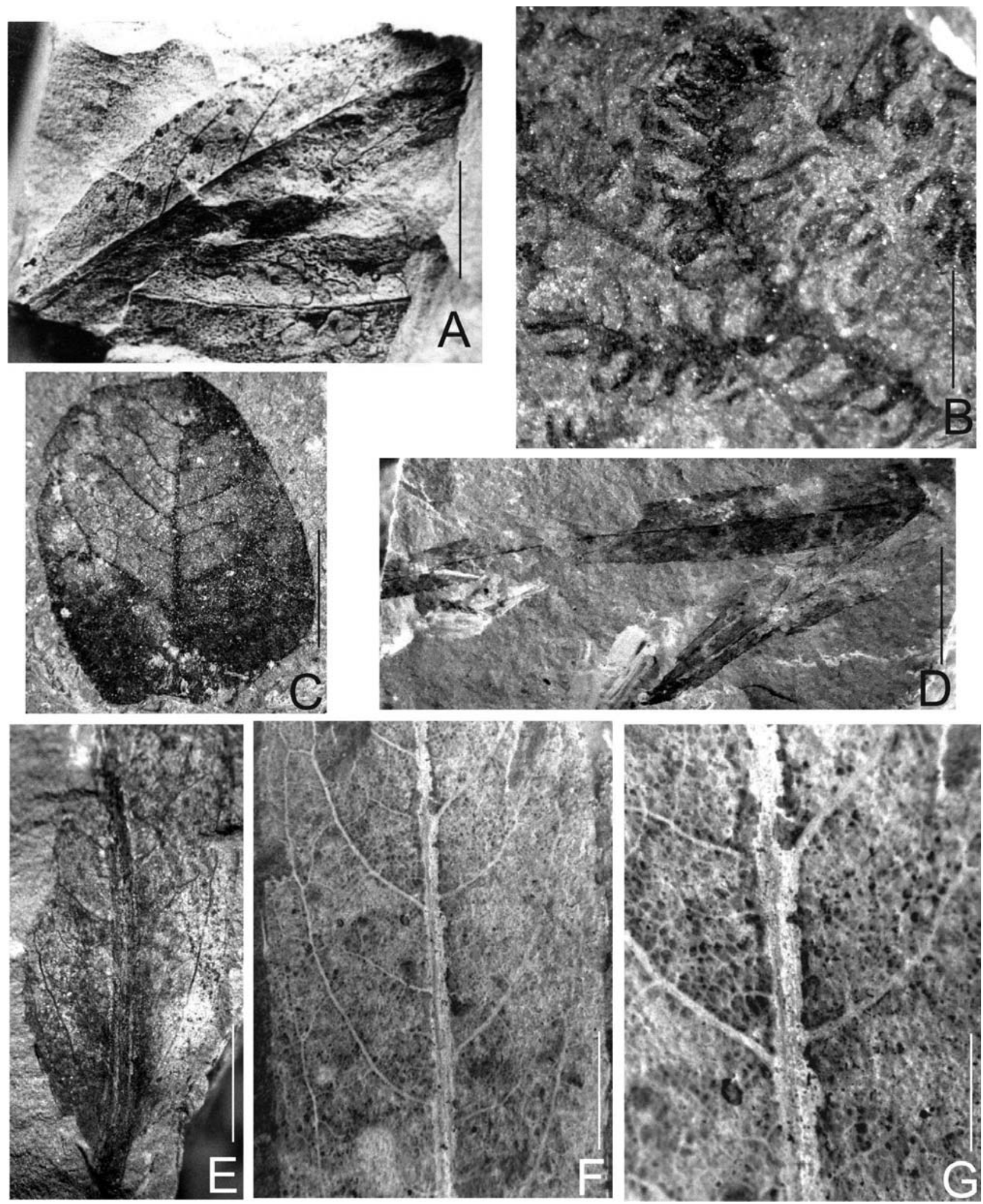

Figura 4. A, D-G, Sapium haematospermoides sp. nov.: A, dos fragmentos de la misma hoja CTES-PB 10795 paratipo; D, hoja parcialmente plegada CTES-PB 10791a holotipo; E, porción basal con detalle de la venación CTES-PB 10798; F-G, detalle de venación con imagen invertida CTES-PB 10792. B, Lycopodiella aff. L. cernua (L.) Pich. Serm CTES-PB 12839a. C, Caesalpinia aff. C. stuckerti Hassler CTESPB 12834a. Escalas: $A=1,1 \mathrm{~cm} ; B=0,4 \mathrm{~cm} ; C, F=0,5 \mathrm{~cm} ; D=7 \mathrm{~cm} ; E=0,9 \mathrm{~cm} ; G=0,2 \mathrm{~cm}$.

Figure 4. A, D-G, Sapium haematospermoides sp. nov.: A, two fragments of the same leaf CTES-PB 10795 paratype; D, partially folded leaf CTES-PB 10791a holotype; E, portion of the base, venation detail CTES-PB 10798; F-G, venation detail with inverted image CTES-PB 10792. B, Lycopodiella aff. L. cernua (L.) Pich. Serm CTES-PB 12839a; C, Caesalpinia aff. C. stuckerti Hassler CTES-PB 12834a. Scale bars: $A=1,1 \mathrm{~cm} ; B=0,4 \mathrm{~cm} ; C, F=0,5 \mathrm{~cm} ; D=7 \mathrm{~cm} ; E=0,9 \mathrm{~cm} ; G=0,2 \mathrm{~cm}$. 
Descripción. Hoja linear, ápice atenuado y base cuneada con pecíolo márgenes enteros y lisos, bases de tricomas distribuidas por toda la lámina. Venación pinnada eucamptódroma (las secundarias próximas al margen y en sentido apical disminuyen gradualmente de grosor, se conectan a las secundarias suprayacentes por proyecciones de venas terciarias, sin que constituyan un ciclo de ojales marginales); vena media de tamaño fuerte a masivo (4\% o mas); de recorrido recto, contiene estrías longitudinales. Veinte o más venas secundarias emergen de la vena media con ángulos agudo-moderados $\left(45^{\circ}-60^{\circ}\right)$, los primeros pares basales y los últimos apicales divergen con ángulos agudoangostos $\left(20^{\circ}\right)$; venas intersecundarias simples, emergen de la vena media con ángulos agudo-moderados a anchos, generalmente son opuestas a las secundarias y se unen a las terciarias; las venas terciarias emergen de la vena media, de las secundarias e intersecundarias, tienen un modelo reticulado al azar. Venas cuartarias de trayectoria reticulada ortogonal. La venación última marginal está constituida por venas de tercer orden y es ojalada, las areolas, desde triangulares a hexagonales, están bien desarrolladas.

Dimensiones. Hojas de 6-11 cm de largo por 0,7-1,5 cm de ancho; pecíolo de $0,2 \mathrm{~cm}$ de largo; vena media $0,1 \mathrm{~cm}$ de ancho.

Comparaciones. Berry (1937), en la Formacion Solimões (Eoceno inferior/Plioceno) de Brasil, halló Sapium(?) pliocenica Berry, y la describió como un hoja de $5 \mathrm{~cm}$ x $3,5 \mathrm{~cm}$ largo por ancho, más o menos orbicular, de base amplia y ápice acuminado, pero ilustra sólo el área apical; de cualquier manera, por la forma mencionada, es diferente a la especie aquí descripta. Duarte (1970) expresa que en la colección de vegetales fósiles de Acre (Brasil), no se hallaron el tipo, ni el paratipo. En la paleoflora sudamericana, no se mencionan otros hallazgos de hojas fósiles referidos al género Sapium. Entre las especies actuales del género la forma fósil es parecida por el tipo de venación tanto a $S$. haematospermum Müll. Arg., como a S. glandulosum (L.) Morong., no obstante por la forma de la hoja, la especie fósil, se encuentra en la variabilidad que presenta la primera especie; pero se diferencia de ambas por la presencia de bases de tricomas. Se crea esta nueva especie por la abundancia del material fósil, y porque por la forma es más semejante a $S$. haematospermum, siendo el carácter que las diferencia la presencia de bases de tricomas. Hábito y distribución de las especies actuales afines. Sapium haematospermum y $S$. glandulosum, son árboles que integran los bosques de ribera en el norte argentino (Kruijt, 1996; Zuloaga \& Morrone, 1999).

Orden SAPINDALES Juss. ex Bercht. \& J. Presl., 1820

Familia MELIACEAE Jussieu, 1789

Cedrela P. Browne, 1756

Cedrela fissiliformis sp. nov. (Figuras 2C,E, 5A-E)

Holotipo. Quebrada del Estanque CTES-PB 8028a (base). Paratipo. Quebrada del Estanque CTES-PB 8028c (ápice).
Otro material estudiado. Quebrada del Estanque CTES-PB $8013 ; 8015 ; 8016 ; 8018 ; 8025 ; 8028$ b y d; 8029; $12809 ; 12810$. Quebrada del Horno CTES-PB 12812; 12816.

Etimología. Hace alusión a la similitud con la especie actual Cedrela fissilis Vell.

Diagnosis. Pinnately compound leaf, even-pinnate. Leaflets narrow oblong to lorate (notophylla); attenuate apex; asymmetrical base concavo-convex with petiolule, margin entire and smooth. Pinnate venation weak brochidodromous; midrib moderate size straight course, slightly curved at apex. Twelve or more secondary veins emerge from the midrib, in opposite to subopposite, with sharp angles more open in the basal and apical regions, than average; vein spacing irregular.Secondary veins near the margin are related to each other with weak branches; however, the apical area has more pronounced arches. Tertiary venation percurrente alternate, course sinous; quaternary veins alternate percurrent. Areolas 4-6 sided, areolation well developed. Marginal ultimate venation looped.

Descripción. Porción apical de hoja compuesta paripinada, con dos folíolos apicales y dos laterales paralelos y subsiguientes a los apicales, todos preservados en su porción media basal, ráquis no conservado. Pínnulas incompletas, se preservan porciones medias basales o medias apicales. La forma de una lámina completa (reconstruida) es oblongaangosta a lorada (micrófilas); ápice atenuado levemente asimétrico, base asimétrica (obtusa en una hemilámina, cuneada en la otra), con pecíolulo, márgenes enteros y lisos. Venación pinnada débilmente broquidódroma, vena media de $0,1 \mathrm{~cm}$ de ancho y de grosor moderado (1\%), de recorrido recto; aproximadamente 12 o más venas secundarias emergen de la vena media, en forma opuesta a subopuesta, con ángulos agudo-anchos mas abiertos en la región basal y apical $\left(70^{\circ}\right.$ $\left.80^{\circ}\right)$, que en la media $\left(65-70^{\circ}\right)$. Las venas secundarias próximas al margen se relacionan entre sí con ramas débiles; no obstante, las del área apical poseen arcos más pronunciados. En la región basal se observan espacios intercostales irregulares variando entre $0,5-1 \mathrm{~cm}$ y las venas secundarias tienen un recorrido levemente zigzagueante. La venación terciaria es del tipo percurrente alterno; las venas terciarias emergen con ángulo recto, determinando areolas pentagonales a cuadrangulares, cuyo tamaño equivale a la mitad del tamaño del espacio intercostal; la venación de cuarto orden, también es del tipo percurrente alterno. Las areolas, tetra a hexagonales, se encuentran bien desarrolladas. Venación última marginal, cerrada, arqueada.

Dimensiones. Porción de hoja de $16 \mathrm{~cm}$ de largo por $6 \mathrm{~cm}$ de ancho; folíolos: (reconstruidos) de 9-12 cm de largo, porciones media basales de $5-7 \mathrm{~cm}$ de largo, media apicales de 4,5-8 cm de largo, todos miden 2-3 $\mathrm{cm}$ de ancho, pecíolulo de $0,1-0,15 \mathrm{~cm}$ de largo.

Comparación. Se comparan aquí los folíolos, ya que en la literatura fósil no se encuentra mención a hojas compuestas. La flora fósil argentina cuenta con tres especies de Cedrela: C. mexicaniformis Berry y C. pichileufuana Berry, de la 
Formación Auca Pan, Eoceno inferior (Berry, 1938); y C. sp., de Chenque-Niyeu, Mioceno inferior (Fiori, 1940). Por otro lado, en la flora brasileña se encuentran dos especies: $C$. campbeli Berry, de la Formación Fonseca, Eoceno del Estado de Minas Gerais (Berry, 1935); y C. arcuata Duarte \& RezendeMartins (en Duarte \& Rezende-Martins, 1983), de la Formación Tremembé, Oligoceno; en la flora Miocénica de Venezuela (Estado de Anzoategui) Berry (1939) describe C.preodorata
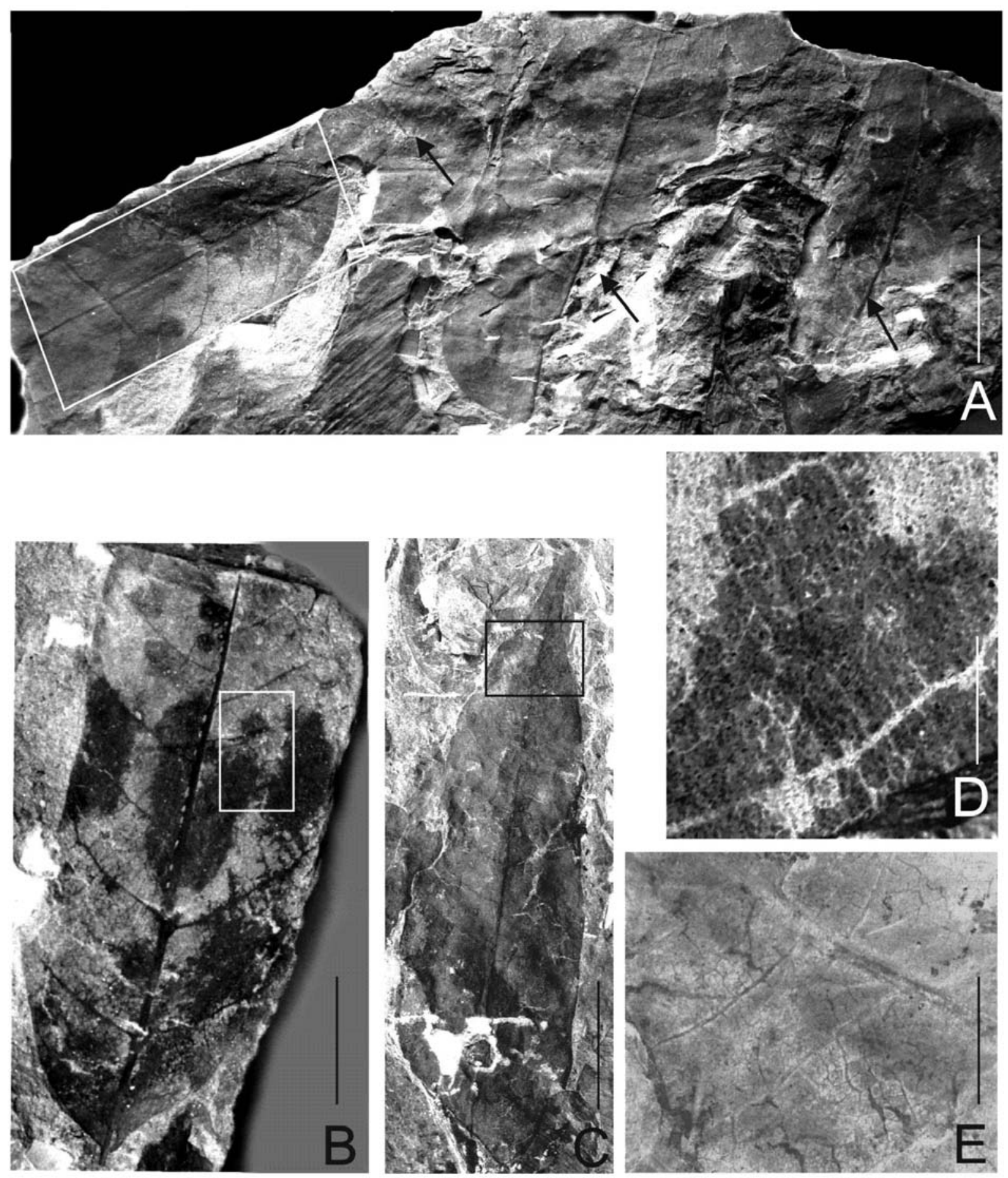

Figura 5. A-E, Cedrela fissiliformis sp. nov.: A, porción apical de la hoja compuesta, el recuadro señala la posición del holotipo, las flechas la de los restantes folíolos CTES-PB 8028a; B, porción media basal de un foliolo, el recuadro señala la posición del detalle en figura D, CTES-PB 8028c holotipo; C, porción media apical de un foliolo, el recuadro señala la posición del detalle en figura E, CTES-PB 8028a paratipo; D-E, detalle de la venación del holotipo y paratipo con imagen invertida. Escalas: $A=7,5 \mathrm{~cm} ; B=1,5 \mathrm{~cm} ; C-E=1,4 \mathrm{~cm}$.

Figure 5. A-E, Cedrela fissiliformis sp. nov.: A, apical portion of the compound leaf, the framed area shows the position of the holotype, and the other leaflets are arrowed CTES-PB 8028a; B, basal middle portion of a leaflet, the framed area indicates the position of the detail in Figure D CTES-PB 8028a holotype; C, apical-medial portion of a leaflet, the framed area is shown in detail in figure E CTES-PB 8028c paratype; D-E, venation detail of holotype and paratype with inverted image. Scale bars: $A=7,5 \mathrm{~cm} ; B=1,5 \mathrm{~cm} ; C-E=1,4 \mathrm{~cm}$. 
Berry. Los caracteres comunes con los de las láminas aquí descriptas son las bases asimétricas, los ángulos de divergencia de las venas secundarias que son mayores de $45^{\circ}$, los espacios intercostales irregulares y la venación terciaria percurrente. C. mexicaniformis, C. pichileufuana y C. campbeli comparten también el tamaño (10 cm o más), pero difieren de la aquí descripta por la forma ovada a ovadaelongada, por el ápice agudo, por la venación principal eucamptódroma y por contener menor cantidad de venas secundarias (6-8) de disposición alterna; particularmente, $C$. mexicaniformis y $C$. campbeli son más anchas; $C$. sp., $C$. arcuata y $C$. preodorata, son más pequeñas y están incompletas, la primera tiene forma oval y venación craspedódroma y la segunda, aunque broquidódroma, posee venas intersecundarias. Por otra parte, las descripciones e ilustraciones de Berry $(1935,1938)$ y Fiori (1940) no ofrecen mayores detalles para una comparación más detallada.

En la flora actual argentina la familia Meliaceae (Pennington, 1981) cuenta con tres especies de Cedrela que contienen hojas compuestas paripinadas; las láminas de la especie fósil se parecen más, por el tamaño, tipo de base y ápice, tipo de venación, ángulo de emergencia de secundarias y terciarias en las áreas basal y apical, tamaño variable de los espacios intercostales basales, a C. fissilis y C. odorata L. y entre ellas por el mayor desarrollo de las areolas (aunque es un carácter menor) es más semejante a la primera de las especies. Por la abundancia, buena preservación de los folíolos o de las láminas foliares, y porque sus caracteres son comunes entre ambas especies actuales, se crea esta nueva especie fósil.

Hábitat y hábito de las especies actuales afines. Cedrela fissilis y $C$. odorata son árboles integrantes de bosques higrófilos o selvas del norte argentino (Pennington, 1981).

\section{DISCUSIÓN Y CONCLUSIONES}

\section{Aspectos taxonómicos}

Desde el punto de vista taxonómico de megafósiles, en esta paleoflora se deben destacar los aspectos discutidos abajo.

Se hallan formas que representan novedad en el registro fósil tanto de Argentina como de Sudamérica, tales como Lycopodiella aff. L. cernua, Acrostichum paleoaureum, Mayaca aff. M. fluviatilis, Cabomba aff. C. caroliniana y Sapium haematospermoides sp. nov. Con respecto a esta última especie, Berry (1937) en la región de Acre (Plioceno) de Brasil, ilustra una porción apical de hoja a la que denominó Sapium(?) pliocenicum Berry, con dudas. Duarte (1970), en una revisión, expresa que esta sería una especie no tipificada ya que en la colección de vegetales fósiles de Acre, no se hallaron el tipo, lectotipo o neotipo; por lo tanto, $S$. haematospermoides sp. nov. se convierte en la primer cita segura del género en el registro fósil de América.

Se encuentran géneros con antecedentes en el registro fósil de América del Sur, tales como Blechnum, Cedrela, Caesalpinia y Equisetum. El género Blechnum tuvo un registro geográfico amplio en el Eoceno de Sudamérica, fue hallado en Brasil, Argentina, Chile y también en Antártida (Engelhardt, 1891; Frenguelli, 1941; Duarte \& Mello Filha, 1980; Baldoni et al., 1985; Troncoso, 1986, 1992); mientras que en el Mioceno, en Venezuela, Chile y Argentina (Berry, 1921; Troncoso, 1991 y este trabajo). No obstante, se debe resaltar que $B$. serrulatiformis sp. nov., particularmente se registra en el Eoceno de Chile (Troncoso, 1992) y en el Mioceno superior del NW de Argentina. De este breve análisis surgen dos observaciones: una se refiere a que el género, en el Eoceno, ya se encontraba diversificado, dada la afinidad botánica actual de las especies fósiles (Tabla 1) y otra a que la especie actual $B$. serrulatum (afín a $B$. serrulatiformis $\mathrm{sp}$. nov.) aparentemente se extinguió en ambos lugares (Chile y noroeste de Argentina), ya que actualmente crece en el noreste argentino, en las provincias de Corrientes y Chaco (Rolleri \& Prada, 2006). No obstante, su distribución es más amplia en el resto del mundo; incluso por la afinidad que brinda Berry (1921), ya se hallaba en el Mioceno de Venezuela.

El género Cedrela tiene un registro continuo desde Eoceno al Plioceno (Tabla 2) y es llamativo que la mayoría de los autores mencionan a $C$. odorata como su afín actual (si bien Berry, 1938 mencionó a C. mexicana, esta especie actualmente se encuentra en sinonimia de aquella, según Penington, 1981); no obstante, ninguna de las especies fósiles es similar entre si, y como en este trabajo $C$. fissiliformis sp. nov., resultó afín a $C$. odorata y $C$. fissilis, surge la posibilidad de que quizá en el Mioceno superior no se haya producido, aún, la diversificación del género. Tal vez una revisión del mismo aporte más elementos para dilucidar esta cuestión. Por último, se debe destacar que Cedrela se habría extinguido en la Patagonia, a partir del Mioceno, por efecto del cambio de las condiciones climáticas (Barreda et al., 2007).

La mención de láminas foliares fósiles asignadas a Caesalpinia se encuentra en el Mioceno de Argentina (Fiori, 1940 y este trabajo), en el Mioceno inferior de Bolivia (Berry, 1919, 1922b) y en el Eoceno de Brasil (Berry, 1935). No obstante, Taylor (1991), para la flora de Bolivia, y Anzótegui et al. (2007), para la de Argentina, sugieren que es necesario realizar una revisión de las fabáceas fósiles debido a la precariedad de sus descripciones e ilustraciones. Confirma esta sugerencia, el hecho de que en Brasil, Fanton et al. (2009), con mayores detalles establecieron que $C$. echinataformis Berry, es afin a Senna multijuga (Rich.) H.S. Irwin \& Barneby.

A pesar de que Equisetites Sternberg tiene una amplia historia en el registro fósil del Mesozoico, Equisetum, en América del Sur, solamente es citado en sedimentos Neógenos: Mioceno de Chile (Troncoso, 1991); Plioceno de Colombia (Berry, 1945); y en Argentina, en el Mioceno superior (Anzótegui, 2006 y este trabajo); en la mayoría de los casos se sugiere que es afín a E. giganteum. De esta revisión se sugiere que sería interesante realizar un estudio exhaustivo entre las especies fósiles y la actual para establecer relaciones y/o diferencias.

Semejante al de Equisetites, es el caso de Lycopodites Lindley \& Hutton 1833, afín al actual Lycopodium L., registrado con frecuencia entre el Paleozoico Superior y Mesozoico; el hallazgo de Lycopodiella, representaría un 
Tabla 1. Registro fósil del género Blechnum en América del Sur y Antártida.

Table 1. Fossil record of the genus Blechnum in South America and Antartica.

\begin{tabular}{|c|c|c|c|c|c|}
\hline Especie & Edad & Formación & Autor & País & $\begin{array}{c}\text { Afinidad botánica } \\
\text { actual }\end{array}$ \\
\hline Blechnum sp. & \multirow{6}{*}{ Eoceno } & & Troncoso, 1986 & Antártida & Sin afinidad \\
\hline $\begin{array}{l}\text { Blechnum. } \\
\text { antidiluvianum }\end{array}$ & & Región de Arauco & Enge lhardt, 1891 & Chile & $\begin{array}{l}\text { B. longifolium } \\
\text { H.B.K. }\end{array}$ \\
\hline Blechnum sp. & & Gandarela & $\begin{array}{l}\text { Duarte y } \\
\text { Mello Filha, } \\
1980\end{array}$ & Brasil & Sin afinidad \\
\hline $\begin{array}{l}\text { Blechnum } \\
\text { (Lomaria) } \\
\text { turbioense }\end{array}$ & & Formación Río Turbio & Frenguelli, 1941 & \multirow[t]{2}{*}{ Argentina } & $\begin{array}{l}\text { B.penna-marina } \\
\text { (Poiret) Kuhn }\end{array}$ \\
\hline Blechnum sp. & & Formación Ventana & $\begin{array}{l}\text { Baldoni et al., } \\
1985\end{array}$ & & $\begin{array}{l}\text { B. australe L. } \\
\text { subesp. } \\
\text { auriculatum } \\
\text { (Cav.) de la Sota }\end{array}$ \\
\hline \multirow{2}{*}{$\begin{array}{l}\text { Blechnum } \\
\text { serrulatiformis } \\
\text { sp. nov. }\end{array}$} & & $\begin{array}{l}\text { Quinamavida, VII } \\
\text { región }\end{array}$ & Troncoso, 1992 & Chile & \multirow[t]{2}{*}{$\begin{array}{l}\text { Blechnum } \\
\text { serrulatum }\end{array}$} \\
\hline & $\begin{array}{l}\text { Mioceno } \\
\text { Superior }\end{array}$ & Palo Pintado & Este trabajo & Argentina & \\
\hline Blechnum sp. & \multirow[t]{2}{*}{ Mioceno } & Formación Navidad & Troncoso,1991 & Chile & $\begin{array}{l}\text { B. asplenoides } \\
\text { Sw.; B. } \\
\text { blechnoides Bory } \\
\text { ex Keyserl.; } B . \\
\text { mochaenum } \\
\text { Kunkel } \\
\end{array}$ \\
\hline B. betijoquensis & & $\begin{array}{l}\text { Betijoque (estado de } \\
\text { Trujillo) }\end{array}$ & Berry, 1921 & Vene zuela & $\begin{array}{l}\text { B. serrulatum y } B \text {. } \\
\text { brasiliense Desv. }\end{array}$ \\
\hline
\end{tabular}

Tabla 2. Registro fósil del género Cedrela en América del Sur.

Table 2. Fossil record of the genus Cedrela in South America.

\begin{tabular}{|c|c|c|c|c|c|}
\hline Especie & Edad & Formación/localidad & Autor & País & $\begin{array}{c}\text { Afinidad } \\
\text { botánica actual }\end{array}$ \\
\hline $\begin{array}{l}\text { Cedrela } \\
\text { pichileufuana }\end{array}$ & \multirow[t]{2}{*}{$\begin{array}{l}\text { Eoceno } \\
\text { Temprano }\end{array}$} & \multirow[t]{2}{*}{ Auca Pan } & \multirow[t]{2}{*}{ Berry, 1938} & \multirow[t]{2}{*}{ Argentina } & Indeter minada \\
\hline $\begin{array}{l}\text { Cedrela } \\
\text { mexicaniformis }\end{array}$ & & & & & \multirow{3}{*}{ C. odorata } \\
\hline Cedrela arcuata & Oligoce no & Tremembé & $\begin{array}{l}\text { Duarte y Rezende- } \\
\text { Martins, } 1983\end{array}$ & \multirow[t]{2}{*}{ Brasil } & \\
\hline Cedrela campbeli & Eoceno & Fonseca & Berry, 1935 & & \\
\hline Cedrela sp. & $\begin{array}{l}\text { Mioceno } \\
\text { Inferior }\end{array}$ & Chenque-Niyeu & Fiori, 1940 & \multirow[t]{2}{*}{ Argentina } & Indeter minada \\
\hline $\begin{array}{l}\text { Cedrela fissiliformis } \\
\text { sp. nov. }\end{array}$ & $\begin{array}{l}\text { Mioceno } \\
\text { Superior }\end{array}$ & Palo Pintado & Este trabajo & & $\begin{array}{l}\text { Cedrela fissilis } \\
\text { C. odorata }\end{array}$ \\
\hline Cedrela preodorata & Plioceno & Loc. Anzoategui & Berry, 1921 & Venezuela & C. odorata? \\
\hline
\end{tabular}

testigo de la diversificación de la familia Lycopodiaceae en el Mioceno superior.

\section{Paleocomunidades}

Relacionando el habito y hábitat de los vegetales actuales afines a los fósiles aquí descriptos y de acuerdo a lo expresado en Galli et al. (2011), ellos representan a cuatro tipos de paleocomunidades: dulceacuícola, palustre, bosque de ribera y xerofítica; en estas paleocomunidades se incluyen además los taxones hallados previamente (Herbst et al., 1987; Anzótegui, 1998). La paleocomunidad dulceacuícola, habría estado integrada por Cabomba aff. C. caroliniana y Mayaca aff. M.fluviatilis, que son vegetales sumergidos y arraigados, y por Salvinia graui y S. cf. S. minima, que son flotantes. La palustre por Equisetum sp., Blechnum serrulatiformis sp. nov., Acrostichum paleoaureum, Lycopodiella aff. L. cernua y ciperáceas, que son vegetales herbáceos. El bosque de ribera por Schinus herbstii en el estrato arbustivo, Cedrella fissiliformis sp. nov., Sapium haematospermoides sp. nov., Nectandra saltensis y Ficus tressensii, en el estrato arbóreo, y Ranunculodendron anzoteguiae, como trepadora. La comunidad xerofítica cuenta por primera vez con un representante en la megaflora, como es Caesalpinia aff. $C$. stuckerti; al respecto se debe agregar que las tres impresiones 
disponibles son de tamaño pequeño (leptófilo) y se hallaron en forma dispersa en diferentes estratos, de ellas sólo una se encuentra bien preservada, por lo que se infiere que los vegetales parentales habrían crecido en ambientes abiertos alejados de los cuerpos ácueos y que las hojas habrían sido transportadas por el viento.

Por último, es de destacar que la mayoría de las especies actuales afines a las fósiles tienen distribución subtropical y tropical en América del Sur y, como ya se demostró en algunos casos, cuentan con antecesores en las paleofloras de Brasil (Blechnum sp. y Cedrela arcuata) y Venezuela (Blechnum betijoquensis y Cedrela preodorata). Argumentos que refuerzan lo ya expresado en Starck \& Anzótegui (2001) y Galli et al. (2011), acerca de que la paleoflora de la Formación Palo Pintado, se desarrolló bajo un clima subtropical húmedo con estacionalidad corta, en mejores condiciones que las de las otras formaciones coetáneas (Chiquimil, en Mautino 2010 y El Morterito, en Anzótegui et al., 2007) del noroeste argentino.

\section{AGRADECIMIENTOS}

Agradecemos a R. Herbst, por su apoyo y colaboración constante. A M.E.C. Bernardes de Oliveira y T. Dutra, por responder con amabilidad y celeridad a nuestros requerimientos bibliográficos y a los árbitros por sus valiosos comentarios. Este trabajo fue realizado en el marco de los proyectos PI96/07 (Secretaría General de Ciencia y Técnica de la Universidad Nacional del Nordeste) y PICT-UNNE 124 (Universidad Nacional del Nordeste/Agencia Nacional de Promoción Científica y Tecnológica).

\section{REFERENCIAS}

Acevedo, L.T.; Anzótegui, L.M. \& Mautino, L.R. 1998. Análisis palinológico preliminar de la Formación Palo Pintado (Mioceno Superior), en Quebrada del Estanque, Salta, Argentina: In: COMUNICACIONES CIENTÍFICAS Y TECNOLÓGICAS, 1998. Resúmenes Expandidos, Corrientes, Universidad Nacional del Nordeste, v. 3, p. 143-146.

Acevedo, T.L.; Mautino, R.L.; Anzótegui, L.M. \& Cuadrado, G.A. 1997. Estudio palinológico de la Formación Palo Pintado (Mioceno Superior), Provincia de Salta, Argentina. Parte II: Esporas. Geociencias, 2:112-120.

Anzótegui, L.M. 1998. Hojas de angiospermas de la Formación Palo Pintado, Mioceno Superior, Salta, Argentina. Parte 1: Anacardiaceae, Lauraceae y Moraceae. Ameghiniana, 35:25-32.

Anzótegui, L.M. 2006. Paleofloras del Mioceno en los Valles Calchaquíes, Noroeste de Argentina. Universidad Nacional del Nordeste, Programa de Posgrado en Biología Tesis Doctoral, $266 \mathrm{p}$.

Anzótegui, L.M. \& Cuadrado, G.A. 1996. Palinología de la Formación Palo Pintado, Mioceno Superior, Provincia de Salta, República Argentina. Parte I: taxones nuevos. Revista Española de Micropaleontología, 28:77-92.

Anzótegui, L.M.; Garralla, S. \& Herbst, R. 2007. Fabaceae de la Formación El Morterito, (Mioceno Superior) del Valle del
Cajón, Provincia de Catamarca, Argentina. Ameghiniana, 44:183196.

APG III, 2009. An update of the Angiosperm Phylogeny Group classification for the orders and families of flowering plants. Botanical Journal of the Linnean Society, 161:1-17. doi: 10.1111/ j.1095-8339.2009.01000.x

Arbo, M.M.; López, M.G.; Schinini, A. \& Piesko, G. 2002. Las plantas hidrófilas. In: M.M. Arbo \& S.G. Tressens (eds.) Flora del Iberá, Editorial de la Universidad Nacional del Nordeste (EUDENE), p. 9-110.

Baldoni, A.M.; Dibbern, M. \& Genini, A. 1985. Nota sobre una especie de Blechnum (Blechnaceae-Pteridophyta) e impronta de Fagus subferruginea Dusen en el Terciario de la Provincia de Chubut, Argentina. Ameghiniana, 22:229-232.

Barreda, V.; Anzótegui, L.M.; Prieto, A.R.; Aceñolaza, P.; Bianchi, M.M.; Borromei, A.M.; Brea, M.; Caccavari, M.; Cuadrado, G.A.; Garralla, S.; Grill, S.G.; Guerstein, G.R.; Lutz, A.I.; Mancini, M.V.; Mautino, L.R.; Ottone, E.G.; Quattrocchio, M.E.; Romero, E.J.; Zamaloa, M.C. \& Zucol, A. 2007. Diversificación y cambios de las Angiospermas durante el Neógeno en Argentina, In: S. Archangelsky; T. Sanchez \& E. Tonni (eds.) Asociación Paleontológica Argentina, Publicación Especial 11, Ameghiniana, 50 aniversario, p. 173-191.

Berry, E.W. 1919. Fossil plants from Bolivia and their bearing upon the age of uplift of the Eastern Andes. Proceedings of the United States National Museum, 54:103-164.

Berry, E.W. 1921. Tertiary fossil plants from Venezuela. Proceedings of the United States National Museum, 59:553-579.

Berry, E.W. 1922a. Pliocene fossil plants from Eastern Bolivia. Johns Hopkins University, Studies in Geology, 4:145-186.

Berry, E.W. 1922b. Late Tertiary plants from Jancocata, Bolivia. Johns Hopkins Universit, Studies in Geology, 4:205-221.

Berry, E.W. 1935. Tertiary plants from Brazil. Proceedings of the American Philosophical Society, 75:565-590.

Berry, E.W. 1937. Late Tertiary plants from the Territory of Acre, Brazil. Johns Hopkins University, Studies in Geology, 12:81-90.

Berry, E.W. 1938. Tertiary flora from the Rio Pichileufú, Argentina. Geological Society of America, Special Paper, 12:1-149.

Berry, E.W. 1939. Fossil plants from the State of Anzoategui, Venezuela. Johns Hopkins University, Studies in Geology, 13:137-155.

Berry, E.W. 1945. Late Tertiary fossil plants from Eastern Colombia. Johns Hopkins University, Studies in Geology, 14:171-194.

Cabrera, A.L. 1976. Regiones fitogeográficas argentinas. Tomo II, Fascículo 1. Enciclopedia argentina de agricultura y jardineira. Buenos Aires, Editora Acme, 85 p.

Coutand, I.; Caparra, B.; Diiken, A.; Schmitt, A.K.; Sobel, E.R. \& Strecker, M.R. 2006. Propagation of orographic barriers along and active range front: insights from sandstone petrography and detrital apatite fission-track thermochronology in the intramontane Angastaco basin, NW Argentina. Basin Research, 18:1-26. doi:10.1111/j.1365-2117.2006.00283.x

Cronquist, A.; Takhtajan, A. \& Zimmermann, W. 1966. On the higher taxa of Embryobionta. Taxon, 15(4):129-134.

Díaz, J.I. 1985. Análisis estratigráfico del Grupo Payogastilla, Terciario Superior del Valle Calchaquí, Provincia de Salta, República Argentina: In: CONGRESO GEOLÓGICO CHILENO, 4, 1985. Actas, Antofagasta, v. 1, p. 211-234.

Díaz, J. I. 1987. Estratigrafía y sedimentología del Terciario Superior de la región comprendida entre los valles de los ríos Calchaquí y Guachipas, Provincia de Salta, Republica Argentina. 
Universidad Nacional de Tucumán, Programa de Posgrado en Geología, Tesis Doctoral, 198 p.

Diaz, J.I. \& Malizzia, D.C. 1983. Estudio geológico y sedimentológico del Terciario Superior del Valle Calchaquí (Departamento San Carlos, Prov. de Salta). Boletín Sedimentológico del Instituto de Geología, Facultad de Ciencias Naturales, Universidad Nacional del Tucumán, 2:8-28.

Dizeo de Sttrimatter, C. 1973. Nueva técnica de diafanización. Boletín de la Sociedad Argentina de Botánica, 15:126-129.

Duarte, L. 1970. Coméntarios sobre o "status" taxinômico de una coleção de vegetais fósseis do Acre. Anais da Academia Brasileira de Ciências, 42:471-476.

Duarte, L. \& Mello Filha, M.C. 1980. Flórula Cenozóica de Gandarela, Minas Gerais. Anais da Academia Brasileira de Ciências, 52:77-91.

Duarte, L. \& Pimentel de Rezende-Martins, A.F. 1983. Contribuição ao conhecimento da Flora Cenozóica do Brasil: Jazigo Vargem Grande do Sul, SP: Série Taubaté. I. Anais da Academia Brasileira de Ciências, 55:109-121.

Engelhardt, H. 1891. Ueber Tertiärpflanzen von Chile. Abhandlungen der senckenbergischen naturforschenden Gesellschaft, 16:629-692.

Fantón, J.C.; Ricardi Branco, F.; Francischetti García, R.J. \& Moreira Silva, A. 2009. Arquitectura y anatomía foliar de Leguminosae eocénica, Cuenca de Fonseca, sureste del Brasil: In: SIMPOSIO ARGENTINO DE PALEOBOTÁNICA Y PALINOLOGÍA, 14, 2009. Libro de Resúmenes, p. 20.

Fiori, A. 1940. Filliti Terziarie della Patagonia III -Filliti di ChenqueNiyeu. Giornale di Geologia, Annali del Museo Geologico di. Bologna, 14:94-143.

Frenguelli, J. 1941. Nuevos elementos florísticos del Magellaniano de Patagonia Austral. Notas del Museo de La Plata, 6:174-202.

Galli, C.I.; Anzótegui, L.M.; Horn, M.Y. \& Morton, L.S. 2011. Paleoambiente y paleocomunidades de la Formación Palo Pintado (Mioceno-Plioceno), Provincia de Salta, Argentina. Revista Mexicana de Ciencias Geológicas 28:161-174.

Galli, C.I.; Ramírez, A.; Barrientos, C.; Reynolds, J.; Viramonte, J.G. \& Idleman, B. 2008. Estudio de proveniencia de los depósitos del Grupo Payogastilla (Mioceno Medio-Superior) aflorantes en el Río Calchaquí, Provincia de Salta, Argentina: In: CONGRESO GEOLÓGICO ARGENTINO, 17, 2008. Actas, Neuquén, p. 353-354.

Garcia Massini, J.L.; Jacobs, B.F.; Pan, A.; Tabor, N. \& Kappelman, J. 2006. The occurrence of the fern Acrostichum in Oligocene volcanic strata of the northwestern Ethiopian Plateau. International Journal Plant Science, 167:909-918.

Herbst, R.; Anzótegui, L.M. \& Jalfin, G. 1987. Estratigrafía, paleoambientes y dos especies de Salvinia Adanson (Filicopsida) del Mioceno Superior de Salta, Argentina. Revista de la Facultad de Ciencias Exactas y Naturales y Agrimensura (FACENA), 7:15-42.

Hickey, L.J. 1979. A revised classification of the architecture of Dicotyledonous leaves. In: C.R. Melcalfe \& L. Chalk (eds.) Anatomy of the Dicotyledons 1, Clarendon Press, p. 25-39.

Hoehne, F.C. 1955. Plantas Aquáticas. Instituto de Botânica, Secretaria da Agricultura do Estado de São Paulo, 168 p.

Kruijt, R.C. 1996. A taxonomic monograph of Sapium Jacq., Anomostachys (Baill.) Hurus., Duvigneaudia J. Léonard and Sclerocroton Hochst. (Euphorbiaceae tribe Hippomaneae).
Stuttgart, Bibliotheca Botanica 146, E. Schweizerbart'sche Verlagbuchhandlung, $109 \mathrm{p}$.

LAWG (Leaf Architecture Working Group), 1999. Manual of leaf architecture: morphological description and categorization of dicotyledoneous and net-veined monocotyledonous angiosperms. Washington, Smithsonian Institution, $65 \mathrm{p}$.

Lutz, A.I. \& Martinez, L.C.A. 2007. Nuevo género y especie de liana del Mioceno Superior (Formación Palo Pintado), Provincia de Salta, Argentina. Ameghiniana, 44:205-213.

Mautino, L.R. 2010. Palinofloras de las formaciones San José y Chiquimil (Mioceno medio y superior), Noroeste de Argentina. Universidad Nacional del Nordeste, Programa de Posgrado en Biología, Tesis Doctoral, 444 p.

Mohr, B.A.R.; Bernardes-de-Oliveira, M.E.C. \& Taylor, D.W. 2008. Pluricarpellatia, a Nymphaealean Angiosperm from the Lower Cretaceous of Northern Gondwana (Crato Formation, Brazil). Taxon 57:1147-1158.

Morton, L.S. 1992. Bivalvos de agua dulce de la Formación Palo Pintado (Mioceno Tardío) del Valle Calchaquí, Provincia de Salta, Argentina. Revista de la Facultad de Ciencias Exactas y Naturales y Agrimensura (FACENA), 9:77-91.

Nuñez, C.O.; Cantero, J.J. \& Petryna, L. 1998. Los hidrófitos del sur de la Provincia de Córdoba (Argentina). Revista de la Universidad Nacional de Río Cuarto, 18:37-82.

Pennington, T.D. 1981. Meliaceae. Flora Neotrópica. New York, NY Botanical Garden, 470 p. (Monograph 28).

Ragonese, A.E. \& Castiglioni, J.A. 1970. La vegetación del Parque Chaqueño. Boletín de la Sociedad Argentina de Botánica, 11(Suplemento):133-160.

Rolleri, C.H. \& Prada, C. 2006. Catálogo comentado de las especies de Blechnum L. (Blechnaceae, Pteridophyta) de Mesoamérica y Sudamérica. Anales del Jardín Botánico de Madrid, 63:67-106.

Starck, D. \& Anzótegui, L.M. 2001. The late Miocene climatic change persistence of a climatic Signal through the orogenic stratigraphic record in northwestern of Argentina. Journal South American Earth Sciences, 14:763-774. doi:10.1016/S08959811(01)00066-9

Starck, D. \& Vergani, G. 1996. Desarrollo tecto-sedimentario del Cenozoico en el Sur de la Provincia de Salta, Argentina: In: CONGRESO GEOLÓGICO ARGENTINO, 12/CONGRESO DE EXPLORACIÓN DE HIDROCARBUROS, 3, 1996. Actas, Buenos Aires, v. 1, p. 433-452.

Sota, E.R. de la 1977. Pteridophyta. In: A.L. Cabrera (ed.) Flora de la Provincia de Jujuy, República Argentina, Parte 2, Instituto Nacional de Tecnología Agropecuaria, 275 p.

Taylor, D.W. 1991. Paleobiogeographic relationships of Andean angiosperms of Cretaceous to Pliocene age. Palaeogeography, Palaeoclimatology, Palaeoecology, 88:69-84. doi:10.1016/ 00310182(91)90015-J

Troncoso, A. 1986. Nuevas órgano-especies en la tafoflora Terciaria inferior de Península Fildes, Isla Rey Jorge, Antártica. Serie Científica del Instituto Nacional Antártico de Chile, 34:23-46.

Troncoso, A. 1991. Paleomegaflora de la Formación Navidad, Miembro Navidad (Mioceno) en el área de Matanzas, Chile central occidental. Boletín del Museo Nacional de Historia Natural de Chile, 42:131-168.

Troncoso A. 1992. La tafoflora terciaria de Quinamavida (VII Región, Chile). Boletín del Museo Nacional de Historia Natural de Chile, 43:155-178. 
Tryon, R.M. \& Tryon, A.F. 1982. Ferns and allied plants with special reference to tropical America. Berlin, Springer-Verlag, 857 p.

Tur, N.M. 1987. Cabombaceae. In: N. Troncoso \& N. Bacigalupo (eds.) Flora Ilustrada de Entre Ríos, Instituto Nacional de Tecnológico y Agropecuario, 6:303-305.

Urquiola Cruz, A.J. 2000. Las Mayacaceae de Cuba. Anales del Jardín Botánico de Madrid, 58:325-329.

Zuloaga, F.O. \& Morrone, O. 1996. Catálogo de la plantas vasculares de la República Argentina 1. Pteridophyta,
Gymnospermae, y Angiospermae (Monocotiledoneae). Saint Louis, Missouri Botanical Garden, 323 p. (Monographs in Systematic Botany 60).

Zuloaga, F.O. \& Morrone, O. 1999. Catálogo de la plantas vasculares de la República Argentina 2. Dicotyledoneae. Saint Louis, Missouri Botanical Garden, 1269 p. (Monographs in Systematic Botany 74).

Received in February, 2011; accepted in October, 2011. 